\title{
Comunicação
}

[Communication]

\section{Surto de mastite bovina causada por linhagens de Pseudomonas aeruginosa multirresistentes aos antimicrobianos}

[Outbreak of bovine mastitis caused by multiple drug resistant Pseudomonas aeruginosa strains]

\author{
M.C. Fernandes, M.G. Ribeiro, A.K. Siqueira, T. Salerno, G.H.B. Lara, F.J.P. Listoni
}

Faculdade de Medicina Veterinária e Zootecnia - UNESP

Caixa Postal 560

18618-000 - Botucatu, SP

Os microrganismos envolvidos na gênese das infecções mamárias bovinas são classificados convencionalmente como contagiosos e ambientais. Fungos, algas e enterobactérias são os agentes mais frequentes na etiologia das mastites de origem ambiental (Santos e Fonseca, 2007; Ribeiro et al., 2008). A mastite por microrganismos ambientais é transmitida principalmente no intervalo entre-ordenhas, em ambientes com excesso de matéria orgânica, dejetos e umidade (Ribeiro et al., 2006). Pseudomonas aeruginosa são bactérias oportunistas, ubíquas, identificadas em diversas afecções, tanto nos humanos como nos animais, observadas especialmente em quadros de otite, cistite, endometrite, encefalite, linfadenite, mastite, dermatite, abscessos, pneumonia, enterite e septicemia (Radostits et al., 2007). No ambiente, são encontradas preferencialmente na água, no solo e, ocasionalmente, nas plantas. Nos animais, podem ser isoladas das mucosas e fezes (Quinn et al., 2005).

A mastite bovina por Pseudomonas spp. está intimamente relacionada à água contaminada utilizada na lavagem dos tetos, dos insufladores (teteiras), da canalização do equipamento de ordenha, do conteúdo reutilizável de pré ou pósdipping, ou mesmo em cânulas contaminadas durante a terapia intramamária (Quinn et al., 2005; Santos e Fonseca, 2007). A mastite por $P$. aeruginosa é incomum. Entretanto, já foram descritos surtos de mastite com manifestações clínicas graves, hiperagudas, nas primeiras semanas pós-parto. A glândula mamária apresenta-se hiperêmica, edemaciada e sensível à palpação. O leite revela a presença de grumos, pus e mostra-se amarelado a escurecido (Radostits et al., 2007; Sela et al., 2007). Microrganismos do gênero Pseudomonas apresentam comportamento psicrotrófico. Conceitualmente, este grupo de patógenos caracteriza-se pela multiplicação em temperaturas entre 20 a $40^{\circ} \mathrm{C}$, embora sejam hábeis em multiplicar-se às temperaturas de refrigeração indicadas para o armazenamento de alimentos - abaixo de $8^{\circ} \mathrm{C}$ - o que gera grande preocupação para os profissionais da área de inspeção de alimentos e de qualidade do leite (Santos e Fonseca, 2007).

Nos humanos, a ocorrência de $P$. aeruginosa está associada principalmente aos distúrbios entéricos, dermatites pós-queimaduras e osteomielites (Galanakis et al., 1997). Em crianças, indivíduos imunossuprimidos - como pacientes acometidos por neoplasias ou pelo vírus da síndrome da imunodeficiência adquirida (SIDA) - as infecções por $P$. aeruginosa assumem elevada gravidade (Quinn, 1998). A bactéria figura dentre as principais causas de infecções hospitalares. Ademais, classicamente apresenta multirresistência aos principais grupamentos de antimicrobianos convencionais, devido a mutações que determinam linhagens resistentes às drogas derivadas do anel $\beta$ lactâmico e fluorquinolonas (Paul et al., 1997). O presente estudo investigou surto de mastite bovina por linhagens de Pseudomonas

Recebido em 11 de julho de 2008

Aceito em 5 de maio de 2009

Email: martafernandesunesp@hotmail.com 
aeruginosa multirresistentes aos principais antimicrobianos utilizados na terapia da mastite bovina.

Foram encaminhadas ao Serviço de Diagnóstico de Mastite em Animais da FMVZUNESP/Botucatu, SP, 37 amostras de leite de 36 vacas, provenientes de propriedade rural do interior do Estado de São Paulo, com histórico de surto de mastite. O diagnóstico de mastite clínica foi firmado nos animais que apresentaram alterações no leite (presença de grumos, pus, dessoragem ou estrias de sangue) no teste da caneca telada de fundo escuro (Tamis), sinais de inflamação na glândula mamária (dor, edema, hiperemia ou nódulos) e/ou sistêmicos (Radostits et al., 2007). A mastite subclínica foi caracterizada utilizando-se o teste clássico de California Mastitis Test (escores 1+ a 3+) (Schalm et al., 1971). As amostras de leite de vacas com mastite clínica ou subclínica foram semeadas em ágar-sangue bovino desfibrinado (5\%) e ágar MacConkey, incubadas em aerobiose, a $37^{\circ} \mathrm{C}$, por 72 horas. P. aeruginosa foi identificada com base nas características morfotintoriais e bioquímicas (Krieg e Holt, 1984). O perfil de sensibilidade microbiana dos microrganismos isolados foi realizado mediante a técnica de difusão com discos (Performance..., 2003), utilizando-se antimicrobianos disponíveis comercialmente para a terapia intramamária em vacas, a saber: ampicilina $(10 \mu \mathrm{g})$, cefalexina $(30 \mu \mathrm{g})$, cefoperazona sódica $(75 \mu \mathrm{g})$, cloxacilina $(5 \mu \mathrm{g})$, danofloxacina $(5 \mu \mathrm{g})$, enrofloxacina $(5 \mu \mathrm{g})$, florfenicol $(30 \mu \mathrm{g})$, gentamicina $(10 \mu \mathrm{g})$, neomicina $(30 \mu \mathrm{g})$, penicilina/novobiocina $(40 \mu \mathrm{g})$ e tetraciclina $(30 \mu \mathrm{g})$. Foram consideradas multirresistentes as linhagens com resistência simultânea a três ou mais antimicrobianos.

Dos 36 animais avaliados, 30 apresentaram mastite clínica e seis subclínica. Destes, em 19 animais, 16 com mastite clínica e três com mastite subclínica, foram isoladas, com 24 horas de incubação em Agar sangue, colônias irregulares, com bordas serrilhadas, de 1-2mm de diâmetro, de odor cítrico, com presença de halo estreito de hemólise que, em 48 horas, apresentou halo hemolítico pronunciado. No ágar MacConkey, foram observadas com 24 horas de incubação, colônias irregulares, lactosenegativas, produtoras de pigmentos de tonalidade amarelada, esverdeada ou enegrecida. Com base nas características morfotintoriais e bioquímicas, o microrganismo isolado foi classificado como $P$. aeruginosa. Nos demais animais, foi isolada predominantemente Escherichia coli, em cultura pura ou em associação com $P$. aeruginosa. $\mathrm{O}$ cultivo de amostras de água de lavagem dos insufladores (teteiras), do pré e pós-dipping e da canalização do equipamento de ordenha da propriedade, revelou o isolamento de $P$. aeruginosa na solução do pré-dipping e na água utilizada na lavagem dos insufladores.

O perfil de sensibilidade microbiana das 19 linhagens de $P$. aeruginosa (Tab. 1) mostrou que enrofloxacina $(73,7 \%)$ e danofloxacina $(73,7 \%)$ foram os antimicrobianos mais efetivos frente aos microrganismos isolados. $\mathrm{Na}$ totalidade destes, observou-se resistência múltipla a cinco ou mais dos antimicrobianos utilizados.

Tabela 1. Perfil de sensibilidade microbiana na prova de difusão com discos em 19 linhagens de Pseudomonas aeruginosa isoladas de surto de mastite bovina, Botucatu, SP, 2008

\begin{tabular}{lccc}
\hline \multirow{2}{*}{ Antimicrobiano } & \multicolumn{3}{c}{ Número de linhagens $(\%)$} \\
\cline { 2 - 4 } Ampicilina & Sensível & Parcialmente sensível & Resistente \\
Cefalexina & $0(--)$ & $0(--)$ & $19(100,0)$ \\
Cefoperazona & $0(--)$ & $0(--)$ & $19(100,0)$ \\
Cloxacilina & $4(21,0)$ & $5(26,3)$ & $10(52,6)$ \\
Danofloxacina & $0(--)$ & $0(--)$ & $19(100,0)$ \\
Enrofloxacina & $14(73,7)$ & $4(21,0)$ & $1(5,3)$ \\
Florfenicol & $14(73,7)$ & $5(26,3)$ & $0(--)$ \\
Gentamicina & $1(5,3)$ & $0(--)$ & $18(94,7)$ \\
Neomicina & $0(--)$ & $0(--)$ & $19(100,0)$ \\
Penicilina/novobiocina & $0(--)$ & $5(26,3)$ & $14(73,7)$ \\
Tetraciclina & $0(--)$ & $0(--)$ & $19(100,0)$ \\
\hline
\end{tabular}


Classicamente os casos de mastite por $P$. aeruginosa são descritos como manifestações clínicas agudas, nas primeiras semanas de lactação, com redução abrupta na produção de leite e perda da função glandular (Radostits et al., 2007). De maneira similar, a maioria dos animais do presente estudo apresentou mastite clínica, hiperaguda, com manifestações clínicas graves na glândula mamária e alterações significativas no leite. Este resultado coincide com os achados de outros autores que se referem aos microrganismos ambientais - incluindo $P$. aeruginosa - frequentemente associados aos casos de mastite clínica, hiperaguda, nas primeiras semanas pós-parto (Ribeiro et al., 2006; Santos e Fonseca, 2007). O isolamento de $P$. aeruginosa da solução de imersão do prédipping e da água utilizada na limpeza dos insufladores da ordenha está em consonância com outros autores que afirmaram que a água utilizada no ambiente de ordenha dos animais é uma das principais vias de transmissão do agente para a glândula mamária (Radostits et al., 2007; Santos e Fonseca, 2007).

A multirresistência dos 19 isolados foi verificada para ampicilina, cefalexina, gentamicina, tetraciclina, penicilina/novobiocina e cloxacilina. Estes antimicrobianos não-efetivos frente aos isolados compõem os principais princípios ativos utilizados na terapia intramamária de vacas no Brasil, na lactação e no período seco, fato que dificulta sobremaneira a instituição da terapia intramamária contra $P$. aeruginosa (Ribeiro, 2008). Tanaka et al. (2002) investigaram o perfil de sensibilidade in vitro de linhagens de $P$. aeruginosa isoladas de diferentes afecções em animais - incluindo casos de mastite bovina - e encontraram resistência múltipla das linhagens para ampicilina, tetraciclina e enrofloxacina, e sensibilidade para a gentamicina. A elevada resistência dos 19 isolados de $P$. aeruginosa é similar aos achados de outros estudos, que também assinalaram multirresistência do agente aos antimicrobianos de uso em medicina humana e/ou veterinária (Paul et al., 1997; Radostits et al., 2007), fato que pode ser creditado à resistência da bactéria, principalmente aos fármacos do grupo das fluorquinolonas e derivados do anel betalactâmico.

Enrofloxacina e danofloxacina foram os antimicrobianos efetivos frente aos 19 microrganismos isolados. Em que pese a efetividade in vitro observada para estas quinolonas, a eficácia in vivo na terapia mamária ou parenteral nas infecções mamárias por $P$. aeruginosa é reduzida. Diante da ineficácia da terapia convencional com antimicrobianos e na vigência de casos de mastite pelo microrganismo, recomenda-se a secagem abrupta das fêmeas acometidas, a ablação química dos quartos afetados ou mesmo o descarte dos animais infectados, somados às medidas de controle e profilaxia para microrganismos de origem ambiental na casuística de mastite (Ribeiro, 2008).

Nos últimos anos, com a necessidade de prazo de validade mais longo, a conservação do leite e derivados é um dos principais desafios da indústria de laticínios. A contaminação da matéria prima por psicrotróficos, como o gênero Pseudomonas, que se multiplica em temperaturas de refrigeração $\left(4-8^{\circ} \mathrm{C}\right)$ - indicada no estoque de alimentos - e produz enzimas lipolíticas $\mathrm{e}$ proteolíticas, que determinam à degradação e depreciação do produto, constitui problema emergente para os profissionais da área de inspeção sanitária e de qualidade do leite (Santos e Fonseca, 2007). A presença de surto de mastite bovina por linhagens de $P$. aeruginosa, multirresitentes, e de potencial zoonótico, inclusive em animais com mastite subclínica cujo leite pode inadvertidamente ser enviado para o laticínio ou consumo in natura -, reforça a importância para os procedimentos de controle e profilaxia de mastite em rebanhos leiteiros. Perante a caracterização de surto clássico de mastite bovina por microrganismo de origem ambiental, foram recomendadas várias medidas específicas para o controle deste patógeno na propriedade, quais sejam: a retirada diária de dejetos e matéria orgânica do ambiente de ordenha, desinfecção das instalações; substituição do recipiente de imersão do prédipping por outro que não permita o refluxo do antisséptico; higienização ao final da ordenha dos recipientes de pré e pós-dipping; oferecimento de alimento para as vacas na pósordenha; cloração da água de uso no ambiente de ordenha; pavimentação e retirada diária de dejetos do ambiente da pré e pós-ordenha.

Palavras-chave: bovino, Pseudomonas aeruginosa, surto, mastite, resistência a antimicrobianos 


\begin{abstract}
Uncommon outbreak of mastitis caused by Pseudomonas aeruginosa strains in 19 cows was reported. Enrofloxacin (73.7\%) and danofloxacin were in vitro effective against those strains. In vitro multiple drug resistance of the isolated bacteria was observed to five or more conventional antimicrobials used for mammary therapy, including ampicillin (100.0\%), cefalexin (100.0\%), cloxacillin (100.0\%), gentamicin (100.0\%), penicillin/novobiocin (100.0\%), cefoperazone (52.6\%), tetracycline (100.0\%), florfenicol (94.7\%), and neomycin (73.7\%). Epidemiological findings, clinical signs, in vitro susceptibility profile, control measures, and public health risks were discussed in cows infected by $\mathrm{P}$. aeruginosa.
\end{abstract}

Keywords: bovine, Pseudomonas aeruginosa, outbreak, mastitis, drug resistance

\section{REFERÊNCIAS BIBLIOGRÁFICAS}

GALANAKIS, N.; GIAMARELLOU, H.; MOUSSAS, T. et al. Chronic osteomyelitis caused by multi-resistant Gram-negative bacteria: evaluation of treatment with newer quinolones after prolonged follow-up. $J$. Antimicrob. Chemother., v.39, p.241-246, 1997.

KRIEG, N.R.; HOLT, J.G. (Eds). Bergey's manual of systematic bacteriology. London: Williams \& Wilkins, 1984. 984p.

PAUL, S.; BEZBARUAH, R.L.; ROY, M.K. Multiple antibiotic resistance (MAR) index and its reversion in Pseudomonas aeruginosa. Lett. Appl. Microbiol., v.24, p.169-171, 1997.

PERFORMANCE standards for antimicrobial disk susceptibility test (CLSI-NCCLS). 8.ed. Wayne, PA: Clinical and Laboratory Standards Institute, 2003.

QUINN, J.P. Clinical problems posed by multiresistant nonfermenting gram-negative pathogens. Clin. Infect. Dis., v.27, p.117-124, 1998.

QUINN, P.J.; MARKEY, B.K., CARTER, M.E. et al. (Eds). Microbiologia veterinária e doenças infecciosas. Porto Alegre: Artmed, 2005. 512p.

RADOSTITS, O.M.; GAY, C.C.; HINCHCLIFF, K.W. et al. (Eds). Veterinary medicine: A textbook of the diseases of cattle, horses, sheep, pigs, and goats. 10.ed. Philadelphia: W.B. Saunders, 2007. p.724-725.
RIBEIRO, M.G. Princípios terapêuticos na mastite em animais de produção e de companhia. In: ANDRADE, S.F. (Ed). Manual de terapêutica veterinária. 3.ed. Roca: São Paulo, 2008. p.759-771.

RIBEIRO, M.G.; COSTA, E.O.; LEITE, D.S. et al. Fatores de virulência em linhagens de Escherichia coli isoladas de mastite bovina. Arq. Bras. Med. Vet. Zootec., v.58, p.724-731, 2006.

RIBEIRO, M.G.; MOTTA, R.G.; PAES, A.C. et al. Peracute bovine mastitis caused by Klebsiella pneumoniae. Arq. Bras. Med. Vet. Zootec., v.60, p.485-488, 2008.

SANTOS, M.V.; FONSECA, L.F.L. (Eds) Estratégias para controle de mastite e melhoria da qualidade do leite. São Paulo: Manole, 2007. $314 \mathrm{p}$.

SCHALM, O.W.; CARROL, E.J.; JAIN, N.C. Bovine mastitis. Philadelphia: Lea \& Febiger, 1971. 360p.

SELA S.; HAMMER-MUNTZ, O.; KRIFUCKS, $\mathrm{O}$. et al. Phenotypic and genotypic characterization of Pseudomonas aeruginosa strains isolated from mastitis outbreaks in dairy herds. J. Dairy Res., v.74, p.425-429, 2007.

TANAKA, E.M.; RIBEIRO, M.G.; MEGID, J. et al. Tris-EDTA no teste de sensibilidade antimicrobiana in vitro em amostras de Pseudomonas aeruginosa. Arq. Bras. Med. Vet. Zootec., v.54, p.331-334, 2002. 